\title{
COMO ESTÁ CARACTERIZADA ATUALMENTE A PESQUISA SOBRE A FORMAÇÃO DE PROFESSORES NO BRASIL?
}

\author{
Aline Souza da Luz - PPGE/UFPEL ${ }^{1}$ \\ Maria das Graças C. S. Medeiros Gonçalves Pinto - PPGE/UFPEL ${ }^{2}$
}

\section{INTRODUÇÃO}

A formação de professores, como tema de pesquisa, tem apresentado ao longo das décadas diversas possibilidades de investigação, o que tem produzido um volume grandioso de discussões de autores da área, tanto nacional como internacional. No presente trabalho, interessa saber: Como tem sido discutida a formação inicial de professores nesses espaços? Que aspectos têm sido observados sobre esta temática nesses estudos e pesquisas?

$\mathrm{Na}$ busca por responder as questões propostas, o presente trabalho constitui-se numa pesquisa bibliográfica, organizado em trabalho tipo Estado da Arte. As pesquisas tipo "Estado da Arte" buscam realizar investigações mais amplas, contemplando: eventos científicos, periódicos, teses, dissertações, entre outros, apresentando, portanto, maior abrangência. (Romanowski e Ens, 2006). Esse tipo de estudo é importante, pois sistematiza as diferentes análises já realizadas que estão dispersas e fragmentadas.

Para as reflexões e análises, parte-se do exame do conjunto de estudos e de pesquisas sobre formação de professores que mapearam: os estudos tipo estado da arte, analisando teses e dissertações dos programas de pós-graduação em educação; as análises dos trabalhos apresentados em eventos (ENDIPE, ANPED); e grupos de pesquisa. Em suma, analisa-se uma série de estudos que realizam um mapeamento dos estudos e de pesquisas sobre a formação de professores no Brasil. Consideram-se os estudos de: Romanowski (2012; 2013), Diniz Pereira (2013), André (et. al. 1999; 2009; 2010a, 2010b); Brzezinski (2009, 2014), Brzezinski e Garrido (2001), Ramalho, et.al (2002); Ludke et.al. (2011), Oliveira (2002), Soares (2002).

\footnotetext{
${ }^{1}$ Programa de Pós-Graduação em Educação. Universidade Federal de Pelotas. Email: alineluz.ufgrs@gmail.com

${ }_{2}$ Programa de Pós-Graduação em Educação. Universidade Federal de Pelotas.

Email:profgra@gmail.com
} 
Tanto Brzezinski (2009) como Gatti (2014) nomeiam de meta- análise este processo de revisar estudos e pesquisas que já foram mapeados. A metodologia de análise dos trabalhos incide numa "reconciliação integrativa" que, segundo André et. al (1999, p. 308 ): "Consistem num balanço do conhecimento, baseado na análise comparativa de vários trabalhos, sobre uma determinada temática".

O mapeamento abaixo organiza esses estudos, os seus respectivos objetos de investigação e o período investigado, a fim de auxiliar na compreensão da análise realizada por este trabalho.

\section{1 - Teses e dissertações:}

André et. al (1999, 2009)

Romanowski $(2012,2013)$

Romanowski $(2012,2013)$

Diniz-Pereira (2013)

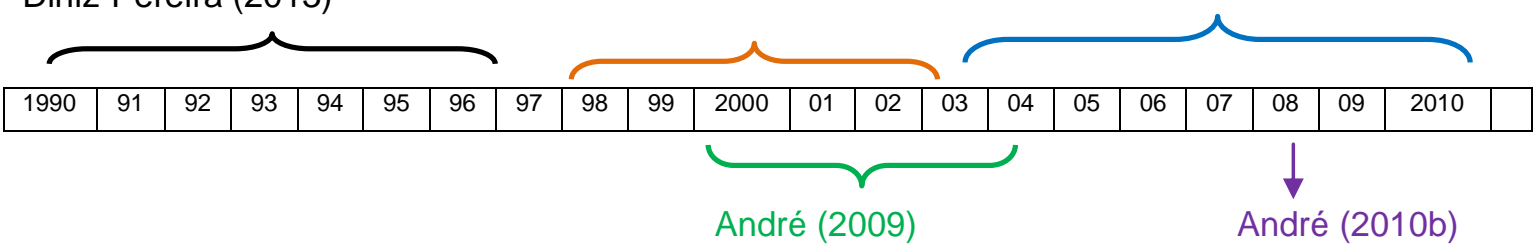

\section{2 - Grupos de Pesquisa:}

I e II Simpósio de Grupos de Pesquisa sobre Formação de professores

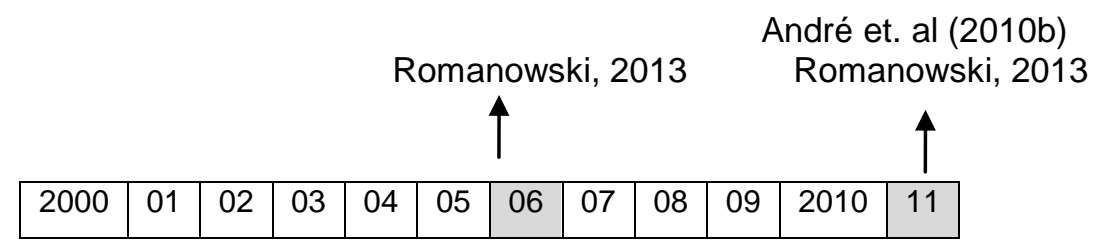

\section{3 - Trabalhos do GT Formação de Professores da ANPED}

Romanowski (2013)

Diniz-Pereira (2013)

Brzezinski, Garrido (2001) Romanowski (2013)

André et. al (1999) Brzezinski (2009)

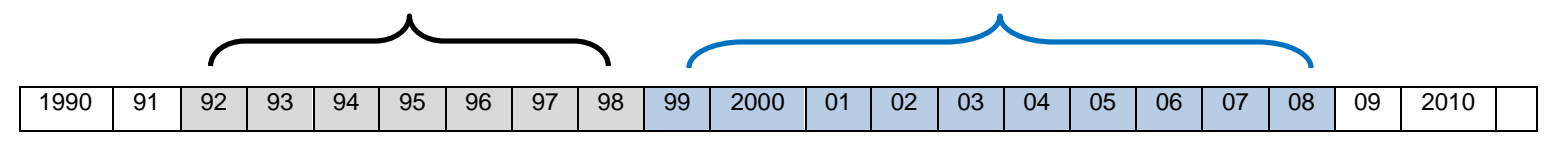

5 - ENDIPE:

Oliveira (2002)

Soares (2002) 


\section{O que indicam as pesquisas e estudos sobre a formação inicial dos professores?}

Das análises feitas sobre as teses e dissertações, organizou-se o quadro abaixo. Nele é possível encontrar as obras analisadas (referenciando o autor e ano da publicação); o período analisado; as categorias de análise e os percentuais de distribuição das pesquisas nas categorias, o que configura, nessa análise, o foco das pesquisas. As células coloridas, no quadro, correspondem às categorias mais pesquisadas, ou seja, destacam o foco das pesquisas.

Quadro 1 - Estudos analisados:

\begin{tabular}{|c|c|c|c|c|c|}
\hline & $\begin{array}{l}\text { André et. } \\
\text { al. (1999) }\end{array}$ & $\begin{array}{l}\text { André } \\
\text { (2009) }\end{array}$ & $\begin{array}{l}\text { André } \\
\text { (2010b) }\end{array}$ & $\begin{array}{c}\text { Brzezinski } \\
\text { (2014) }\end{array}$ & $\begin{array}{c}\text { Brzezinski } \\
\text { (2014) }\end{array}$ \\
\hline $\begin{array}{l}\begin{array}{r}\text { Período } \\
\text { analisado }\end{array} \\
\text { Categorias de } \\
\text { análise }\end{array}$ & 1990-1996 & $1999-2003$ & 2007 & $2003-2007$ & $2008-2010$ \\
\hline Formação inicial & $76 \%$ & $22 \%$ & - & $16 \%$ & $29 \%$ \\
\hline $\begin{array}{l}\text { Formação } \\
\text { continuada }\end{array}$ & $14,8 \%$ & $21 \%$ & - & $14 \%$ & $12 \%$ \\
\hline $\begin{array}{l}\text { Identidade e } \\
\text { profissionalização } \\
\text { docente. }\end{array}$ & $9,2 \%$ & $41 \%$ & $53 \%$ & $22 \%$ & $18 \%$ \\
\hline Trabalho docente & - & - & - & $30 \%$ & $23 \%$ \\
\hline $\begin{array}{l}\text { Políticas e proposta } \\
\text { de formação de } \\
\text { professores }\end{array}$ & - & - & - & $13 \%$ & $10 \%$ \\
\hline $\begin{array}{l}\text { Políticas de } \\
\text { formação }\end{array}$ & - & $4 \%$ & - & - & - \\
\hline $\begin{array}{l}\text { Concepções de } \\
\text { docência e de } \\
\text { formação de } \\
\text { professores }\end{array}$ & - & - & - & $3 \%$ & $7 \%$ \\
\hline $\begin{array}{l}\text { Formação inicial e } \\
\text { continuada }\end{array}$ & - & $3 \%$ & - & - & - \\
\hline Outros & - & $9 \%$ & - & - & - \\
\hline Revisão da literatura & - & - & - & $2 \%$ & $1 \%$ \\
\hline
\end{tabular}


Os cinco (5) estudos apresentados constituem a base das análises sobre a produção discente. $O$ esforço da sistematização integrativa dos estudos e pesquisas consultados, realizado pelo presente trabalho, permite inferir que 0 número de pesquisas sobre formação de professores tem crescido na área da educação. Essa constatação reforça a formação de um campo de conhecimentos sobre a formação de professores, legitimando um conjunto de conhecimentos consistentes sobre o campo a partir da realidade brasileira. A existência de discussões teórico-epistemológicas da temática demarca a existência de um debate mais profundo sobre a formação de professores, superando os discursos que centram somente no domínio do conhecimento específico ou mesmo o domínio de técnicas didático-pedagógicas com que, por vezes, tem sido tomada a formação de professores.

Outro aspecto a ser salientado, do conjunto de estudos e de pesquisas, indica que de maneira geral, a produção discente sobre a formação de professores mantém três (3) categorias de análise, como base: (1) a formação inicial, (2) a formação continuada e (3) a identidade e profissionalização docente com inserção de outras categorias ao longo do período estudado (1990 - 2010), ou seja, 20 anos de pesquisa sobre as produções discente. Na primeira metade da década de 1990, a produção discente se configura nas três categorias já anunciadas. Na segunda metade da década de 90, surgem em menor incidência, estudos sobre políticas para formação de professores e, a partir do ano 2003, incluem-se outras categorias de análise, tais como: concepções de docência e de formação de professores; políticas e propostas de formação de professores; trabalho docente e revisão de literatura. A categoria políticas para formação de professores é redirecionada para categoria de políticas e propostas de formação de professores.

Há um consenso entre os autores, à medida que analisam as produções discentes sobre a formação de professores, que, ao longo dos anos, o foco de investigação passou dos cursos para o professor. Ao mesmo tempo em que são importantes os estudos que evidenciem aspectos mais específicos do sujeito professor, há a necessidade também de mais pesquisas sobre que processos e práticas de formação de professores seriam mais efetivos no contexto atual da 
educação brasileira. São raras as investigações que procuram pesquisar os aspectos teóricos que marcam a formação de professores. Ou seja, poucos estudos produzidos pelas mais diversas instâncias estão preocupados com os debates teóricos que compõem a formação de professores.

André (2009), por exemplo, num estudo de análise comparativa de teses e dissertações dos programas de pós-graduação em educação do país, investigou os trabalhos do período entre 1999 - 2003 e comparou os resultados encontrados com seu estudo anterior (ANDRÉ et. al, 1999), em que também investigou teses e dissertações do período entre 1990-1998. Em mais de uma década de análise, a autora concluiu:

Se, nos anos 1990, a grande maioria das pesquisas se debruçava sobre os cursos de formação inicial (72\%), nos anos 2000, a maior parte dos trabalhos investiga questões relacionadas a identidade e profissionalização docente $(41 \%)$. Houve uma mudança de foco dos cursos de formação para os docentes e seus saberes (ANDRÉ, 2009, p. 48).

Do estudo de Brzezinski (2014), destaca-se o aparecimento da categoria "concepções de docência e de formação de professores". Ela desponta na produção discente de forma incipiente, agregando ainda poucos trabalhos: no primeiro grupo somente 19 pesquisas e no segundo grupo somente 15. Nessa categoria são considerados em ambos os grupos, 2003-2007 e 2008 -2010, os seguintes temas: a) os fundamentos epistemológicos, sociológicos, históricos, antropológicos, psicológicos, entre outros; b) os fundamentos didáticos e metodológicos de ensino das diferentes áreas das Ciências Humanas e Sociais, ciências-aporte da Educação e da Pedagogia. Constata-se, a partir do estudo de Brzezinski (2014), que volta a aparecer a preocupação com os processos e fundamentos da formação docente.

Entretanto, ao concluir seu estudo das teses e dissertações da primeira década dos anos 2000, Brzezinski (2014) lança uma preocupação:

Incongruentemente, os trabalhos dos doutorandos e mestrandos deixam uma lacuna muito grande no tocante aos estudos teóricos sobre a formação docente, que possam verticalizar referenciais sobre 0 objeto: os fundamentos epistemológicos, didáticos e metodológicos da formação docente, bem como as concepções sobre formação de formadores de professores. (BRZEZINSKI, 2014) 
Outro aspecto a salientar dos estudos refere-se à categoria da formação inicial. O quadro a seguir busca clarificar como a referida categoria tem se configurado ao longo dos anos, nos respectivos estudos analisados. Cabe salientar que os cursos estão dispostos em ordem descrente, o que se refere, ao volume de incidência em que aparecem nas pesquisas.

Quadro 2 -

\begin{tabular}{|c|c|c|c|c|c|}
\hline & $\begin{array}{c}\text { André et. al. } \\
(1999)\end{array}$ & $\begin{array}{l}\text { André } \\
(2009)\end{array}$ & $\begin{array}{c}\text { André } \\
\text { (2010b) }\end{array}$ & $\begin{array}{c}\text { Brzezinski } \\
(2014)\end{array}$ & $\begin{array}{c}\text { Brzezinski } \\
(2014)\end{array}$ \\
\hline $\begin{array}{l}\text { Período } \\
\text { analisado } \\
\text { Categorias } \\
\text { de análise }\end{array}$ & 1990-1996 & $1999-2003$ & 2007 & 2003-2007 & $2008-2010$ \\
\hline $\begin{array}{l}\text { Formação } \\
\text { inicial }\end{array}$ & $\begin{array}{c}1^{\circ} \text { curso } \\
\text { normal de } \\
\text { nível médio, } \\
2^{\circ} \\
\text { licenciaturas } \\
3^{\circ} \text { pedagogia }\end{array}$ & $\begin{array}{c}\text { 10 licenciatura } \\
2^{\circ} \text { pedagogia } \\
3^{\circ} \text { curso } \\
\text { normal de } \\
\text { nível médio, } \\
4^{\circ} \text { curso } \\
\text { normal de } \\
\text { nível superior }\end{array}$ & - & $\begin{array}{c}1 \text { o pedagogia } \\
22^{\circ} \\
\text { licenciatura } \\
3^{\circ} \text { curso } \\
\text { normal de } \\
\text { nível médio, }\end{array}$ & $\begin{array}{c}\text { 10 pedagogia } \\
\text { presencial } \\
\text { 20 pedagogia } \\
\text { EAD } \\
3^{\circ} \\
\text { licenciatura }\end{array}$ \\
\hline
\end{tabular}

Fonte: os autores

A categoria formação inicial se configurou até o ano de 2007, com cursos presenciais de Pedagogia, Licenciaturas e Curso Normal. A partir desse ano, surge a modalidade de Educação a Distância (EAD), principalmente pelo incentivo que esses cursos têm recebido das políticas educacionais. É preciso avançar nos estudos sobre essa modalidade, principalmente percebendo as implicações para a formação dos professores.

Com a ênfase no texto da LDB, da formação de professores em nível superior, o curso normal cedeu lugar como lócus da formação de professores das séries iniciais da educação básica, para os cursos de Pedagogia. Nas pesquisas e investigações dessa área, cresce a necessidade de compreender esses cursos que passam a ter maior evidência na formação dos professores, bem como os cursos de licenciatura. Por isso, a partir do ano de 1999, as investigações da formação inicial centram suas análises em cursos de pedagogia e licenciaturas e, mais recentemente, buscam analisar as modalidades de oferta desses cursos. 
Ao compor este cenário com os estudos e pesquisas analisadas, ele revela escassez de produção de conhecimento tanto sobre a formação inicial quanto sobre os processos, concepções e fundamentos da formação de professores. As implicações da ausência de pesquisas sobre essa questão limitam a construção de argumentos e conhecimentos consistentes sobre a Formação de Professores

$\mathrm{Na}$ continuidade de análises, outro espaço de produção científica analisado foram os grupos de pesquisa sobre formação de professores. Sobre esses grupos, encontramos os trabalhos de Romanowski $(2012,2013)$ e André et. al (2010a). Ambos os estudos, analisam os trabalhos apresentados durante a realização do I e II Simpósios de Grupos de Pesquisa sobre Formação de Professores, organizado pelo GT 08 Formação de Professores da Anped, em 2006 e 2011, respectivamente.

O I Simpósio de Grupos de Pesquisas sobre Formação de Professores, realizado na PUC-SP, contou com a participação de 120 pesquisadores, representantes de 70 Grupos de Pesquisa. Já II, realizado na PUC-PR, participaram integrantes de 33 grupos de pesquisa.

Sobre esses eventos, Romanowski (2012, p. 921), conclui:

\begin{abstract}
Nos simpósios de grupos de pesquisa parece que o foco no ensino de áreas do conhecimento específico de atuação profissional dos professores é predominante, isto é, o estudo de metodologias de ensino, da aprendizagem de conteúdos específicos, do currículo, compõe os assuntos investigados. $O$ processo de formação em si não é considerado. A formação de professores é entendida como articulada a área de conhecimento, ou seja, reafirma-se que o estudo dos conteúdos da educação básica e sua didática como pertinentes à docência como condição de suficiência à docência.
\end{abstract}

$\mathrm{Na}$ continuidade de análises, outro espaço de produção científica analisado foram os trabalhos apresentados no GT 8 da ANPED. Sobre esses trabalhos encontramos os estudos de Diniz-Pereira (2013), Romanowski (2013), Brzezinski e Garrido (2001), Brzezinski (2009); André et. al (1999).

A análise dos trabalhos apresentados no GT 8 da ANPED está dividida em dois grupos: o primeiro analisa os trabalhos da década de 1990; já o segundo grupo analisa os trabalhos, em sua grande maioria da primeira década dos anos 2000.

Do primeiro grupo, os trabalhos de André et. al (1999) e Brzezinski e Garrido (2001) apresentam uma 
análise mais detalhada dos trabalhos. Ambos os estudos apontam que foram analisados 70 trabalhos apresentados no GT Formação de Professores no período 1992-1998. Destes, 40\% tratam da formação inicial; 24\% sobre formação continuada; $16 \%$ das pesquisas tratam sobre questões relativas à profissionalização docente; 14\% abordam práticas pedagógicas; 6\% apresentam uma revisão da literatura. Entre os trabalhos que investigam a formação inicial, $58 \%$ focalizaram os cursos de licenciatura, $28 \%$ o curso de pedagogia e $14 \%$ o curso Normal.

Dos trabalhos que investigam as licenciaturas, foram observados os seguintes aspectos:

Os trabalhos sobre licenciatura discutem a dicotomia entre a formação específica e a formação pedagógica, relatam experiências curriculares inovadoras, revelam a importância da interdisciplinaridade nos programas de formação docente, expõem experiências de articulação entre ensino, pesquisa e extensão, debatem as diferenças entre conhecimento científico, saber cotidiano e saber escolar, estudam as representações e opiniões dos alunos da licenciatura. (ANDRÉ et. al, 1999, p. 307)

As análises dessas produções revelam uma preocupação com aspectos da formação, para além da mera descrição da organização e funcionamento dos cursos de formação de professores. Preocupam-se com as discussões acerca dos fundamentos da formação docente, quando "discutem a dicotomia entre a formação específica e a formação pedagógica," ou "debatem as diferenças entre conhecimento científico, saber cotidiano e saber escolar". Oferecem também elementos importantes para pensar os processos formativos desses profissionais quando "relatam experiências curriculares inovadoras, revelam a importância da interdisciplinaridade nos programas de formação docente e expõem experiências de articulação entre ensino, pesquisa e extensão".

O segundo grupo analisa os trabalhos, em sua grande maioria, da primeira década dos anos 2000. Dois textos sistematizam as análises sobre os trabalhos apresentados no GT 8 da ANPED, Romanowski (2013) e Brzezinski (2009). Do primeiro, merece a contribuição desse estudo para a delimitação do campo científico da formação de professores. No segundo texto, Brzezinski (2009), faz uma retomada de todo o período, entre 1992-2008. Para isso, a autora retoma o trabalho anterior (BRZEZINSKI e GARRIDO, 2002) em que analisa de trabalhos do GT da ANPED entre 1992-1998 e traz importantes elementos das análises dos 
trabalhos entre 1999-2008. Nesse período, foram analisados 118 trabalhos divididos em sete categorias, conforme tabela a seguir:

\section{Categorização dos trabalhos, frequência em ordem decrescente - 1999-2008}

\begin{tabular}{lccc} 
CATEGORIAS DE ANÁLISE & $\mathrm{N}$ & $\%$ \\
\hline Identidade e Profissionalização Docente & 26 & 22 \\
\hline Formação Inicial & 24 & 20 \\
\hline Formaçāo Continuada & 21 & 18 \\
\hline Trabalho Docente & 16 & 14 \\
\hline Pollticas de Formaçāo de Profissionais da Educaçāo & 14 & 12 \\
\hline Concepçōes de Docência e de Formação de Professores & 13 & 11 \\
\hline Revisaão de Literatura & 4 & 3 \\
\hline Total & 118 & 100 \\
\hline
\end{tabular}

Fonte: Matriz analitica e ementas das categorias (Brzezinski, 2009)

Importa destacar a categoria "concepções de docência e de formação de professores". Assim como nas teses e dissertações, ela desponta na produção de forma incipiente, agregando ainda poucos trabalhos. Segundo a autora, dois movimentos têm contribuído para que despontem investigações nessa temática. 0 primeiro deles trata sobre a mudança da legislação, principalmente a partir da aprovação das Diretrizes Curriculares Nacionais para a formação de professores, resolução CNE/CP n. 02/2002. Este documento normativo traz em sua redação uma concepção de docência e de formação de professores. Um segundo movimento que tem provocado investigações que abordem "concepções de docência e de formação de professores", trata-se

[...] do próprio movimento da pesquisa sobre a docência e o trabalho docente colocou em cheque o paradigma da racionalidade técnica que caracterizava a formação inicial e continuada do professor. Essas transformações exigiram um profundo repensar sobre as concepções de docência e de formação do profissional. (BRZEZINSKI,2009, p. 87).

A categoria "concepções de docência e de formação de professores", divide-se em dois subtemas: fundamentos didático-metodológicos e fundamentos epistemológicos, antropológicos, históricos, psicológicos, filosóficos, sociológicos. 
$\mathrm{Na}$ tabela abaixo, é possível verificar a incidência de investigações em cada um dos subtemas:

\section{Categorias, descritores, subdescritores por ano. Período 1999 -2008}

Categoria 1. Concepções de Docência e de Formação de Professores

\begin{tabular}{|c|c|c|c|c|c|c|c|c|c|c|c|}
\hline Descritores, Subdescritores & 99 & 00 & 01 & 02 & 03 & 04 & 05 & 06 & 07 & 08 & SubT \\
\hline $\begin{array}{l}\text { 1.1 Fundamentos } \\
\text { epistemológicos, filosóficos, } \\
\text { sociológicos, antropológicos, } \\
\text { históricos, psicológicos }\end{array}$ & 1 & - & 2 & - & - & 1 & - & - & - & 1 & 5 \\
\hline $\begin{array}{l}\text { 1.2 Fundamentos } \\
\text { Didático-metodológicos }\end{array}$ & 1 & 1 & - & 1 & - & 2 & 1 & 1 & 1 & - & 8 \\
\hline TOTAL & 2 & 1 & 2 & 1 & - & 3 & 1 & 1 & 1 & 1 & 13 \\
\hline
\end{tabular}

Percebe-se uma incidência maior de investigações sobre os aspectos didático-metodológicos. Ou seja, os aspectos para o exercício da docência nas diferentes disciplinas da educação básica. Já os aspectos dos fundamentos que versam sobre aspectos teóricos da formação foram menos investigados. Esta percepção vem reforçando a ideia de que são raras as investigações que procuram pesquisar os aspectos teóricos que marcam a formação de professores.

$\mathrm{Na}$ continuidade de análises, outro espaço de produção científica analisado foram os trabalhos do ENDIPE. No estudo de Oliveira (2002) e Soares (2002), as autoras fazem um balanço dos 10 primeiros Endipes e constatam que, a partir do VIII ENDIPE (1996), há um paralelismo nas discussões entre a temática da formação de professores e o campo didático pedagógico. Esse paralelismo marca o surgimento do campo de conhecimento e pesquisa sobre a formação de professores no evento.

Embora se tenha um volume grandioso de pesquisas na temática, quando se faz o recorte para a formação inicial, concentrando as análises sobre as concepções de formação, ou seja, que implicam nos debates sobre aspectos teóricos e fundamentos dessa formação são raras e escassas as investigações.

\section{CONSIDERAÇÕES FINAIS}


Ainda que a pesquisa sobre a formação de professores tenha mais de três (3) décadas de investigações, o que permite reconhecer que possui um conjunto de conhecimentos consistentes; é necessária a continuidade da reflexão teórica sobre o campo da Formação de Professores, sustentada por investigação produzida a partir da realidade brasileira, a fim de consolidar a formação de professores como um campo de conhecimento. A constituição do campo legitima um conjunto de conhecimentos consistentes $\mathrm{e}$, com isso, contribui para valorização da formação e profissão docente, pois evidencia tratar-se de uma profissão com saberes e conhecimentos próprios, superando o consenso de que formar professores exige somente conhecimento específico na área disciplinar que irá lecionar.

\section{REFERÊNCIAS}

ANDRÉ, M. E. D. A. A produção acadêmica sobre formação de professores: um estudo comparativo das dissertações e teses defendidas nos anos 1990 e 2000. Revista Formação Docente, Belo Horizonte, v. 01, n. 01, p. 41-56, ago./dez. 2009. Disponível em: http://formacaodocente.autenticaeditora.com.br. Acesso em: 18 Mai. 2015.

(et. al) . Pesquisa sobre a formação de professores: síntese do II Simpósio de grupos de pesquisa do GT 8 da ANPED. Revista brasileira de pesquisa sobre formação docente. Belo Horizonte, v. 02, n. 03, p. 152, 159, ago/dez. 2010 a. Disponível em: http://formacaodocente.autenticaeditora.com.br. Acesso em: 18 Mai. 2015

Formação de professor: a constituição de um campo de estudos. Educação, Porto Alegre, v. 33, n. 3, p. 174-181, set./dez. 2010 b. Disponível em: http://formacaodocente.autenticaeditora.com.br. Acesso em: 18 Mai. 2015.

(et. al) Estado da arte da formação de professores no Brasil. Educação \& Sociedade. Ano XX, no 68. Dez/99 - p.301 - 309. Disponível em: http://formacaodocente.autenticaeditora.com.br. Acesso em: 18 Mai. 2015.

Brzezinski, I. Formação de profissionais da educação (2003-2010). Brasília: Instituto Nacional de Estudos e Pesquisas Educacionais Anísio Teixeira, 2014. Disponível em: http://formacaodocente.autenticaeditora.com.br. Acesso em: 18 Mai. 2015.

\section{Pesquisa sobre formação de profissionais da educação no GT}

8/Anped: travessia histórica. Revista brasileira de pesquisa sobre formação docente. Belo Horizonte, v. 01, n. 01, p. 71-94, ago/dez. 2009. Disponível em: http://formacaodocente.autenticaeditora.com.br. Acesso em: 18 Mai. 2015.

; GARRIDO, Elza. Análise dos trabalhos do GT Formação de

professores: o que revelam as pesquisas do período 1992-1998. Revista Brasileira 
de Educação, Set/Out/Nov/Dez, 2001 № 18. p. 82 - 100. Disponível em: http://formacaodocente.autenticaeditora.com.br. Acesso em: 18 Mai. 2015.

DINIZ-PEREIRA, Júlio Emílio. A construção do campo da pesquisa sobre a formação de professores. Revista da FAEEBA - Educação e Contemporaneidade, Salvador, v. 22, n. 40, p. 145-154, jul./dez. 2013.

OLIVEIRA, Maria Rita Neto Sales. 20 anos de ENDIPE. IN: CANDAU, Vera M. (org.) Didática, currículo e saberes escolares. Rio de Janeiro: DP\&A, 2002, 2ª ed.

Pp.161-176

RAMALHO, B.L, et.al. A pesquisa sobre a formação de professores nos programas de pós-graduação em educação: o caso do ano 2000. In. 25를 Reunião Anual da Anped, 2002. (trabalho encomendado Gt 08)

ROMANOWSKI, Joana Pauli. Tendencias da pesquisa em formação de professores. ATOS DE PESQUISA EM EDUCAÇÂO - PPGE/ME ISSN 1809-0354 v. 8, n. 2, p.479-499, mai./ago. 2013.

Apontamentos em pesquisas sobre formação de professores:

contribuições para o debate. Rev. Diálogo Educ., Curitiba, v. 12, n. 37, p. 905-924, set./dez. 2012

ROMANOWSKI, J.P.; ENS, R.T. As pesquisas denominadas do tipo "Estado da Arte" em educação. Revista Diálogo Educacional, vol.6, n.19, set.-dez. 2006, pp. 37-50. Disponível em:

$<$ tttp://www2.pucpr.br/reol/pb/index.php/dialogo?dd1=237\&dd99=view\&dd98=pb.> Acesso em 10 de novembro de 2014.

SOARES, Magda. 20 anos de ENDIPE: uma tentativa de compreensão do campo. IN: CANDAU, Vera M. (org.) Didática, currículo e saberes escolares. Rio de Janeiro: DP\&A, 2002,2 ${ }^{\mathrm{a}}$ ed. Pp.177-186. 